\title{
Effects of Implicit Failure Priming on Cognitive and Motor Performance in Elementary School Children
}

\author{
Julia Schüler ${ }^{1}$, Veronika Brandstätter², and Nicola Baumann ${ }^{3}$ \\ ${ }^{1}$ Department of Sport Science, University of Bern, Switzerland, ${ }^{2}$ Department of Psychology, University \\ of Zurich, Switzerland, ${ }^{3}$ Department of Psychology, University of Trier, Germany
}

\begin{abstract}
Previous research showed that failure primes in academic learning contexts can impair the performance of both older school children and college students. The present research tested the effect of failure priming on cognitive and motor performance in elementary school children. We hypothesized that children incidentally confronted with a cue previously learned to indicate failure would perform worse on a cognitive task (Study 1, N=54 second-graders) and a motor task (Study 2, $N=60$ third-graders) than children confronted with a cue indicating success or children in a control group. The results showed that the failure prime group performed worse than the success prime group on an intelligence test (Study 1) and a ball-throwing exercise (Study 2). Neither experimental group differed from the control group. Our studies confirmed previous findings, showing that failure primes can be learned early in life and quickly (e.g., 1 year of failure prime exposure, Study 1). Furthermore, even a one-trial learning process (Study 2) suffices to turn an inherently neutral cue into a failure prime. This failure prime, in turn, can impair different types of performance such as cognitive and motor performance.
\end{abstract}

Keywords: implicit priming, cognitive and motor performance, elementary school children

I have not failed. I've just found 10,000 ways that won't work. Thomas Alva Edison

Although Edison's reappraisal of failure is wise, there are often good reasons to try to avoid failure: Failure is not only associated with disadvantages in one's professional and academic career, but it also has motivational and behavioral consequences (e.g., avoidance motivation and behavior) and results in strong negative emotions (e.g., shame, guilt). In school, failure in terms of bad grades can have several unwanted effects such as feeling depressed, ashamed, and that one's self-worth is threatened (Butler \& Nisan, 1986; Covington, 1992).

Among the various reasons for failure, we are interested in failure primes. Research on indirect priming processes assumes that inherently neutral cues (e.g., colors, letters) can become failure primes due to their long-standing use in performance evaluation in school. Consistent with this assumption, overly learned cues (e.g., the color red, letters or numbers indicating success vs. failure) have been found to work as failure primes impairing the motivation and performance of undergraduate students (Ciani \& Sheldon, 2010; Elliot \& Maier, 2007; Elliot, Maier, Binser, Friedman, \& Pekrun, 2009; Elliot, Maier, Moller, Friedman, \& Meinhardt, 2007; Maier, Elliot, \& Lichtenfeld, 2008; Schü- ler, Brandstätter, \& Baumann, 2013). In the studies cited, the failure primes worked unconsciously in the sense that the undergraduate students were unaware of the priming process, that is, unaware of the relationship between the cue, its meaning, and the consequences.

In the present research, we assumed that avoiding failure at school is so important to elementary school children personally that a long-standing learning history of performance evaluation is not necessary to turn an inherently neutral cue into a failure prime. We tested whether a year of learning (Study 1) and even a single instance of learning to associate neutral cues with successful or failed outcomes (Study 2) is sufficient. We assumed that the failure primes learned in this manner would work the same way the failure primes analyzed in previous research had, that is, by impairing elementary school children's cognitive performance. Besides improving cognitive performance, physical education is also an important aim of elementary education. Because physical inactivity levels during childhood are assumed to influence levels of inactivity and sedentary behavior during adulthood (Kuth \& Cooper, 1992), which in turn is associated with impaired health (Knowler et al., 2002; Powell, Thompson, Caspersen, \& Kenderick, 1987), it seems essential to analyze a potential reason of negative childhood experiences (e.g., fear, bad performance) with sports in school. 


\section{Indirect Priming with Failure Cues in the Academic Learning Context}

The work by Elliot and colleagues (Elliot \& Maier, 2007; Elliot et al., 2007, 2009; Maier et al., 2008) takes into account that subtle environmental cues may prime avoidance tendencies based on the automatic classification of incoming stimuli as unpleasant (Bargh \& Chartrand, 1999; Cacioppo, Gardner, \& Berntson, 1999) and brings together this line of research with the empirical finding that avoidance motivation decreases cognitive performance (Elliot \& Friedman, 2007; Elliot \& McGregor, 1999, 2001; Elliot \& Thrash, 2001). In their studies, Elliot and colleagues (Elliot \& Maier, 2007; Elliot et al., 2007, 2009; Maier et al., 2008) focused on color and assumed that red is associated with negative performance because mistakes are often marked in red ink in the education system, and because individuals have an ingrained evolutionary predisposition to perceiving red as a signal of threat and failure. Because of its association with failure, the color red thus operates as a nonconscious failure prime that automatically evokes an avoidance tendency whenever it appears. The authors hypothesized that this avoidance tendency would in turn impair cognitive performance. To test this, they exposed their participants to the color red versus green or gray (e.g., red, green, or gray cover page of an intelligence test). In accordance with their hypotheses, participants exposed to red subsequently showed higher avoidance motivation (as measured by self-report or by psychophysiological indicators of avoidance motivation) than participants exposed to green or gray. In addition, the evoked avoidance motivation impaired cognitive performance in anagram tasks and a numeric subtest of an intelligence test (e.g., Elliot et al., 2007).

Studies by Ciani and Sheldon (2010) and Schüler et al. (2013) tested the effect of letters and numbers associated with failure on cognitive performance. They found that the letter $\mathrm{F}$, which in the American grading system is associated with failure and which was displayed as a test version symbol on an intelligence test, resulted in decreased motivation and impaired cognitive performance (Ciani \& Sheldon, 2010). Similarly, the number 6, which in the German grading system is associated with failure, and the number 1 , which in the Swiss grading system is associated with failure, impairs performance in analogy tasks when they are displayed as a test version number on the test material (Schüler et al., 2013). In summary, there is strong empirical evidence that widely-used, traditional evaluation symbols (whether letters or numbers) can become failure primes that in turn impair the performance of undergraduate students.

\section{The Present Research}

In the present research, we tested whether inherently neutral cues can become failure cues and thereby even influence the performance of young school children who have a much shorter learning history with failure symbols than do undergraduate students. Study 1 aims to answer the question whether a maximum of 2 years of experience with the school system are enough to learn failure cues and be affected by their consequences. Study 2 tested whether even a unique association between a cue and failure is sufficient to turn an inherently neutral cue into a failure prime that impairs performance. We analyzed cognitive performance (Study 1) and motor performance (Study 2) to demonstrate the generalizability of the failure priming effect across different facets of performance.

We examined the change of a neutral cue into a failure prime in samples of elementary school children. As a result of the critical discussion about whether grading in school has beneficial or detrimental effects on students' performance, well-being, and motivation (Deutsch, 1979; Helmke, 1988; Oosterhof, 1999; Stiggins, 1997; Wagner \& Valtin, 2003), some schools, for example in Switzerland and Germany, do not use grades to evaluate the performance of first- to third-graders and do not introduce the traditional numbered grading system (with grades ranging from 1 to 6) until the fourth grade. However, the evaluation of performance is such an essential feature of academic school life that elementary school teachers do not completely refrain from evaluating their pupils' achievements in the initial years of schooling. In fact, they often use seemingly neutral evaluation symbols to give success or failure feedback to elementary school children. Examples include pictures, stickers, or hand-painted drawings of animals, geometric symbols, colors, or other cues, which are arbitrarily chosen by teachers and inherently unrelated to specific performance evaluations. We assumed that these inherently neutral cues can become failure primes that then impair the elementary school children's performance.

\section{Study 1}

In the first study, we tested second- and third-grade children whose performance in class was evaluated using symbols individually chosen by their teachers. Three classes with different teachers participated. One teacher used pictures of houses (e.g., blocks of flats, single-family homes, and high-rise buildings) to indicate failure and pictures of animals (e.g., stickers or stamps displaying animals such as elephants, horses, cats, and zebras) to indicate success. Another teacher used the color brown for failure and yellow for success. A third teacher symbolized failure with the color green and success with the color red. Please note that the meanings of the colors red and green are reversed here as compared to the meaning theoretically proposed by Elliot et al. (2007, 2009).

We hypothesized that children incidentally confronted with a failure symbol would perform worse on an intelligence test than children confronted with a success symbol. 
We further tested whether the failure symbol group differed from the control group.

\section{Method}

\section{Participants and Procedure}

Thirty-six female and 18 male second- and third-graders with a mean age of 8.4 years $(S D=.79$, range from 7 to 10 years) from three different classes participated in the experiment. The children were tested in their classrooms during a regular lesson. After being introduced by the classroom teacher, the experimenter explained to the children that they would be working on interesting tasks that were similar to puzzles. The experimenter showed them a sample item from Raven's Progressive Matrices and explained that the task was to identify the missing item that completes a pattern. Using two examples, he demonstrated in detail how to perform the task and answered questions.

The children completed a first set of Raven's Progressive Matrices, which was announced as an exercise to prepare for a subsequent test (assessment of T1 performance). After 5 minutes, they were given another test booklet containing a second set of Raven's Progressive Matrices (assessment of T2 performance). The first page of the second test booklet differed depending on the group to which the participants had been randomly assigned. The experimenter explained that different test versions were being used and asked participants to check whether each of the following pages displayed the correct test version symbol. In the failure prime groups, the failure symbols (Class 1: house, Class 2: green, Class 3: brown) were displayed in a black-framed box in the middle of the cover page. In the success prime groups, the success symbols (Class 1: animal; Class 2: red; Class 3: yellow) were displayed in a similar fashion. In the control groups, the color white was displayed in a blackframed box on the cover page. After 5 minutes working on the matrices, participants were asked to stop and answer questions assessing their awareness of the symbol priming and suspicions ("What do you think we were trying to test in our study?" or "Please name the test version symbol.") (adapted from a procedure used by Elliot et al., 2007). Because age and sex had been found to influence performance in previous studies (e.g., Elliot, Shell, Henry, \& Maier, 2005), participant age and sex were recorded. The children were then debriefed in detail, given a small reward, and any remaining questions were answered ${ }^{1}$.

\section{Materials}

Performance was measured using Raven's Progressive Matrices (Raven, Raven, \& Court, 2003). Two parallel 12-item versions were used as practice and test matrices sets. Participants indicated which of four alternative patterns completed a matrix of other patterns. The number of correctly completed patterns served as the performance measure.

\section{Results and Brief Discussion}

\section{Preliminary Analyses}

All participants recalled the test version group correctly and were unaware of the purpose of the study. We analyzed whether experimental groups differed with respect to any of the variables assessed prior to the experimental manipulation. Experimental groups did not differ with respect to cognitive performance at $\mathrm{T} 1, F(2,51)=.53, p=.59, \eta^{2}=$ .02 , but with respect to participant age, $F(2,51)=7.14, p$ $=.002, \eta^{2}=.22$. Participants in the failure prime condition $(M=9.09, S D=.54)$ were older than participants in the success prime condition $(M=8.36, S D=.73)$ and the control condition $(M=8.09, S D=.77)$. Thus, participant age was used as a covariate in the analysis that tested for group effects.

Further analyses tested whether boys and girls differed with respect to cognitive performance and whether participant age was associated with performance. Boys and girls did not differ with respect to performance at $\mathrm{T} 1, F(1,52)$ $=.01, p=.99, \eta^{2}=.001$, or at $\mathrm{T} 2, F(1,52)=.19, p=.66$, $\eta^{2}=.004$. Age was unrelated to performance at T1, $r=.09$, $p=.53$, and at T2, $r=-.02, p=.88$.

\section{Task Performance}

On average, participants solved $10.0(S D=1.65$, ranging from 6 to 12) of the practice matrices at T1 and 9.93 (SD $=1.53$, ranging from 6 to 12 ) of the test matrices at T2. The performance measures were significantly related, $r=.68$, $p=.001$.

An ANCOVA revealed a significant effect of prime type on performance at $\mathrm{T} 2$ after the effect of performance at T1 and participant age were controlled for, $F(2,49)=4.56, p$ $=.015, \eta^{2}=.16$, which is displayed in Figure $1^{2}$. Posthoc tests (LSD) showed that the failure prime group $(M=9.27$, $S D=1.95)$ performed significantly worse than the success

1 The data were collected as part of a broader research project and further variables that do not influence the results reported in this paper were also assessed.

2 In order to investigate whether the reported effect holds true for all of the failure cues, we repeated the ANCOVA separately for each class. The hypothesis was confirmed on a descriptive level for all three classes (Class 1 : house vs. animal: $F(2,18)=1.76, p=.21, \eta^{2}=.23$, failure prime: $M=8.79, S D=1.25$, success prime: $M=10.18, S D=1.25$, control: $M=9.09, S D=1.37$; Class $2:$ green vs. red: $F(2,9)=$ 2.11, $p=.18, \eta^{2}=.32$, failure prime: $M=8.00, S D=1.58$, success prime: $M=10.25, S D=1.71$, control: $M=10.20, S D=1.30 ;$ Class 3 : brown vs. yellow: $F(2,13)=3.28, p=.07, \eta^{2}=.34$, failure prime: $M=10.33, S D=1.63$, success prime: $M=11.00, S D=1.26$, control: $M$ $=10.67, S D=.82$ ). However, due to small sample sizes, the effects did not reach significance. 


\section{Cognitive Performance}

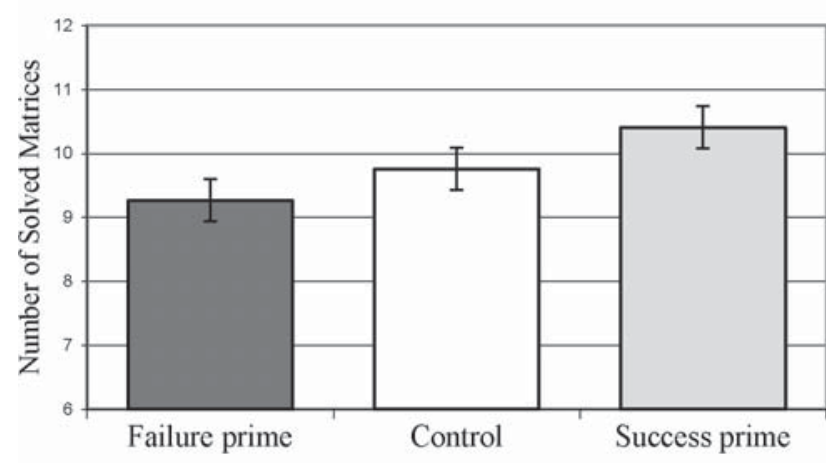

Motor Performance

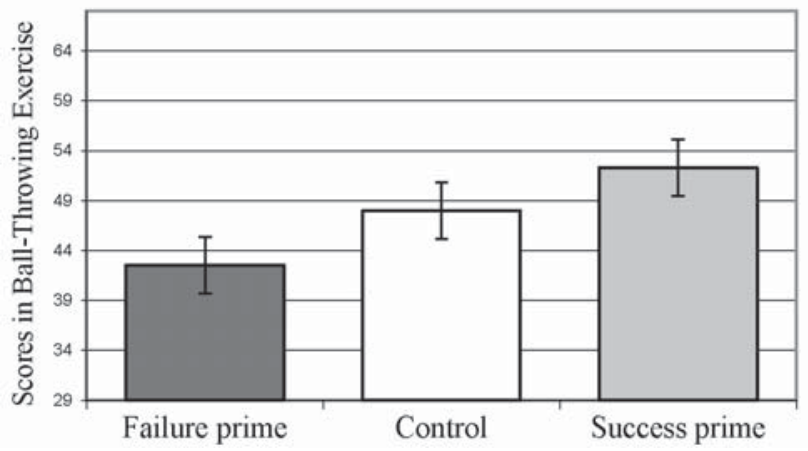

Figure 1. Performance of elementary school children in the failure prime group, success prime group, and in the control group. In Study 1 (upper part) cognitive performance (participants' scores ranged from 6-12) and in Study 2 (lower part) motor performance (participants' scores ranged from 29-68) was assessed.

prime group $(M=10.41, S D=1.26), p=.044$, but it did not differ significantly from the control group $(M=9.76$, $S E=1.44, p=.38$ ). The success prime group and the control group did not differ significantly $(p=.16)$.

Study 1 showed that young children with only a brief learning history of failure cues in school are already affected by failure priming. In Study 2, in order to obtain more information about how cues become failure primes, we drew on the principle of one-trial learning. In order to test the generalizability of the failure priming effect, we investigated motor rather than cognitive performance.

\section{Study 2}

The principle of one-trial learning (Guthrie, 1930; Seligman, 1971) has been widely used in anxiety research to explain the development of phobias. According to this principle, even a single association between a cue and an in- tense threat can suffice to establish a stable association between the two. We assume that failure in achievement settings represents an intense threat for elementary school children that prompts them to learn the association between a neutral cue and failure in a single trial. In order to rule out the possibility that the children might have associated the cue with failure in their past learning history, we chose cues from a totally different domain and used pictures of a spoon and a fork as failure primes.

As a further extension to previous studies that tested cognitive performance as the outcome of failure priming (Elliot et al., 2007, 2009), we assumed that failure primes also affect motor performance. We therefore asked secondand third-graders to throw balls at a target and used the distance to the target center as an operationalization of motor performance.

We again hypothesized that children in the failure prime condition would perform worse than children in the success prime condition and tested whether both groups differed from the control group.

\section{Method}

\section{Participants and Procedure}

A group of 60 second- and third-grade children (boys: $n=$ 32) from four different classes participated in the study, which was announced as a ball-throwing exercise. The participants' mean age was 8.03 years $(S D=1.0$, ranging from 7 to 11 years).

During regular lessons, the children were individually asked to leave class for about $7 \mathrm{~min}$ and were taken to a separate room. Here the experimenter registered the children's age and sex and explained the ball-throwing task. The children were to throw a ball at a target from a fixed distance $(250 \mathrm{~cm}$, which had been revealed to be of medium difficulty for this age group in pretests). They received 5 points if they hit the bullseye, 4 points if they hit the first circle drawn around the bullseye, 3 if they hit the second circle, 2 if they hit the third circle, and 1 point if they did not hit any circles. Participants had 15 trials and the experimenter continuously registered the participants' performance (baseline measure of motor performance) without giving feedback about performance. The experimenter explained that the ball-throwing task was just an exercise to prepare for a "real" test of ball-throwing competence which would take place later.

Then the failure and success prime learning phase began in which the children were to learn to associate neutral cues (spoon, fork) with failure and success. The procedure was as follows: The participants were told that the announced test would be used to assign each child to either the "spoon group" or the "fork group."

If they performed poorly, they would be assigned to the spoon group (i.e., the "loser group"); if they performed well, they would be assigned to the fork group (i.e., the 
"winner group"). Cues as well as success and failure associations were counterbalanced. While explaining the group assignment, the experimenter showed pictures of a fork and a spoon. In addition, either a picture displaying a child showing an unhappy facial expression (failure cue) or a child showing a happy facial expression (success cue) was presented along with the spoon and fork pictures. The experimenter explained that the children in the pictures had been assigned to the fork or spoon group in a previous study and felt correspondingly proud and happy or frustrated and sad. In order to ensure that participants understood the meaning of the cues (i.e., success, failure) correctly, they were asked to repeat the meanings of the groups. Participants were then accompanied back to class.

The testing phase started about 50 minutes later. Participants were randomly assigned to a failure prime group, a success prime group, or a control group. Again, children left class for $7 \mathrm{~min}$ and were accompanied to the experiment room in which either a picture of a fork, a picture of a spoon, or a blank sheet of paper appeared to be randomly positioned at the edge of the table. Participants sat on a chair at a desk with the cue in their field of view and were asked to wait for a couple of minutes until the experimenter had prepared the material. This lasted $2 \mathrm{~min}$. Then participants performed the ball-throwing task again. Afterwards, the experimenter pretended to read through his notes and informed the participant that his/her overall performance was good and that he/she would be assigned to the winner group.

When all of the participants were back in the classroom, the experimenter informed them that their class had performed extraordinarily well, so all of them had been assigned to the winner group. In order to extinguish the association between the cues and failure, the participants were told that group size had to be limited for practical reasons and that therefore two groups - a fork group and a spoon group - had to be created. In the special case of this class, both groups were winner groups. "Fork" and "spoon" were each used twice to indicate that the participants had performed well.

\section{Motor Performance}

The experimenter summed up the scores achieved in the 15 ball-throwing trials in the exercise phase and the test phase. The possible range of scores was from 15 points (when none of the circles around the bullseye were hit) to 60 points (when the bullseye was hit on every trial).

\section{Results}

\section{Preliminary Analyses}

An a priori test showed that the experimental groups did not differ with respect to age, $F(2,57)=.45, p=.64, \eta^{2}=$ .02 , but differed significantly with respect to motor perfor- mance at $\mathrm{T} 1, F(2,57)=3.35, p=.042, \eta^{2}=.11$. At $\mathrm{T} 1$, participants in the failure prime condition $(M=48.80, S D$ $=7.80$ ) showed better performance than participants in the success prime condition $(M=43.00, S D=6.97)$ or the control condition $(M=47.25 .10, S D=7.21)$.

Further analyses tested whether motor performance was associated with participant age or sex. Boys scored descriptively higher than girls in the ball-throwing task at T1 (boys: $M=47.62, S D=7.26$, girls: $M=44.89, S D=7.88$ ), $F(1,58)=1.95, p=.17, \eta^{2}=.03$, and marginally significantly higher at T2 (boys: $M=49.88, S D=9.30$; girls: $M$ $=45.03, S D=10.00), F(1,58)=3.77, p=.06, \eta^{2}=.06$. Participants' age was related to performance at $\mathrm{T} 1, r=.58$, $p=.001$, and at $\mathrm{T} 2, r=.41, p=.001$. In summary, our preliminary analyses suggested that we should control for participants' performance at T1, sex, and age.

\section{Task Performance}

On average, participants scored $46.35(S D=7.62$, range: 32 to 60 ) in the ball-throwing exercise phase and 47.62 ( $S D$ $=9.86$, range: 29 to 68 ) in the test phase. The T1 and T2 motor performance measures were significantly related, $r$ $=.41 p=.001$.

An ANCOVA revealed a significant effect of prime type on motor performance after the effect of performance at T1, participant age, and sex were controlled for, $F(2,54)=$ $24.20, p=.001, \eta^{2}=.47$, which is displayed in the lower part of Figure 1. Posthoc tests (LSD) showed that participants in the failure prime group $(M=42.55, S D=8.09)$ performed significantly worse than participants in the success symbol group $(M=52.30, S D=8.42, p=.001)$ and marginally significantly worse than participants in the control group $(M=48.00, S D=10.73, p=.06)$. The difference between the success symbol group and the control group was not significant, $p=.14$.

\section{General Discussion}

Two studies tested our hypothesis that inherently neutral cues can easily become failure primes, which then impair elementary school children's performance. In a first study, we tested whether second- and third-grade children who were exposed to symbols which their teachers had used in the past to indicate failure (pictures of houses and colors) differed with respect to cognitive performance from children who had been exposed to symbols indicating success (pictures of animals and colors) and children in a control group. As hypothesized, the failure prime group performed significantly worse than the success prime group, but did not differ significantly from the control group.

The first study also showed that the failure prime effect even occurred for the class of school children in which the color red was used to indicate success and the color green 
to indicate failure. This is noteworthy because it seems to be incompatible with some authors' assumption that we can easily associate the color red with failure due to a biological predisposition (Elliot et al., 2007, 2009). The authors stated that, although learned processes (e.g., red ink to mark mistakes) may also contribute to the association between red and failure, these processes are "embedded in a biologically based predisposition across species to interpret red as a danger signal in competitive situations" (Elliot et al., 2009, p. 366). Our study suggests that, even if there is a biological predisposition to link the color red to threat/failure in evaluation settings, it can easily be relearned and become a success prime after a brief learning period in school.

In our second study, we predicted the level of elementary school children's motor performance (scores in a ball-throwing task), which we assumed would depend on whether the children had been briefly exposed to a failure symbol (picture of a spoon) or a success symbol (picture of a fork). As expected, and fully in accordance with the results of Study 1, participants in the failure prime group scored lower than participants in the success symbol group and performed marginally significantly worse than participants in the control group. The study also shows that the process of learning failure and success cues can be very fast. A single association between an inherently neutral cue (e.g., fork, spoon) and failure or success was sufficient to turn neutral cues into failure and success primes. Future research should analyze the stability of a failure prime learned in a single trial. It is plausible that an association learned in a single trial between a cue and a novel meaning is easier to extinguish (e.g., by repeated exposure to a spoon or fork, which are not associated with failure in everyday life) than failure cues that have a longer learning history and are predominantly associated with the performance context.

In summary, our studies confirm the principles of indirect failure priming (Elliot et al., 2007, 2009) (Studies 1 and 2) and one-trial learning (e.g., Seligman, 1970) (Study 2 ), and show that arbitrary cues that are inherently unrelated to failure can become failure primes that, in turn, impair the cognitive and motor performance of elementary school children. However, some of our results warrant further discussion: Whereas in both studies the failure prime groups differed significantly from the success prime groups with respect to cognitive and motor performance, the failure prime groups only differed from the control groups on a descriptive level (exception: marginally significant effect in Study 2 showing that participants in the failure prime condition performed worse than those in the control group). One reason for this might be that our analyses lacked statistical power due to relatively small sample sizes. It could also be argued that we did not consider individual differences in dispositional fear of failure and hope of success, which might have influenced the arousal of approach and avoidance motivation more strongly in the control groups which - in the absence of primes - had no external cues for interpreting the situation. The achievement setting could have elicited performance-impairing avoidance motivation in individuals with a strong fear of failure, whereas in individuals with high hopes of success approach motivation could have facilitated performance. By considering dispositional fear of failure and hope of success as moderators in future research, other research questions could be answered, in particular, whether school children with a high dispositional fear of failure learn failure cues faster or are affected more when confronted with learned failure cues (for the role of fear of failure, see Schüler et al., 2013).

Our results have practical implications for educational settings and for teacher behavior. Teachers may try to avoid evaluating performance using grades and thereby the negative aspects of negative performance feedback in young elementary school students by using feedback cues such as animals, houses, geographic symbols, or colors that indeed seem harmless at first glance. However, we have shown that these may easily function as evaluation criteria that influence the elementary school children's performance like grades do. Both studies confirm the principles of indirect failure priming (Elliot et al., 2007, 2009) and one-trial learning (e.g., Seligman, 1970), and show that arbitrary cues that are inherently unrelated to failure can become failure primes that, in turn, impair the cognitive as well as the motor performance of elementary school children. Learned failure cues constantly threaten the fundamental need for competence, which is essential for children's psychological adjustment and healthy personality development (Deci \& Ryan, 1985, 2000; Ryan \& Deci, 2002, 2008). This may not only affect short-term cognitive and motor performance at school, but could also have a detrimental effect on the child's development in a broader sense and in the long run. They are likely to show similar unwanted reactions to bad grades, such as threatened self-worth and self-esteem (Butler \& Nisan, 1986; Covington, 1992).

Being involved in young children's education (e.g., as a parent or teacher) is a challenging task that also seems to require bearing in mind that less obvious or even unconscious processes exist that affect children's performance and well-being. Because unconscious failure primes might even be unknown to the educator, it is important to be highly sensitive to signs of avoidance motivation (e.g., avoidance behavior) and affect (e.g., fear) and to counter them with means that are under one's (conscious) control, such as providing positive feedback and a benevolent learning atmosphere in order to enhance the child's feeling of competence. Another strategy, which has been shown by selfdetermination researchers to facilitate school children's academic motivation and well-being, is autonomy support provided by teachers (e.g., Kaplan \& Assor, 2012; Reeve, 2009; Vansteenkiste, Niemiec, \& Soenens, 2010; Vansteenkiste et al., 2012). Autonomy-supportive teachers promote their students' will by providing choices, trying to take and understand the students' perspective, and by providing rationales when they have to constrain students' choices. They thereby create a learning atmosphere that is incompatible with fear of failure presumably aroused by failure primes - or at least buffer the negative priming effects. 
Our research leaves an important research question unanswered: What mechanism is responsible for the link between failure symbols and impaired performance? We expect that the same mediator comes into play that has already been found to be relevant for adult samples: avoidance motivation (e.g., Elliot et al., 2007). As in adults, failure primes should also trigger avoidance motivation in elementary school children, which in turn is known to decrease performance (Elliot \& McGregor, 1999, 2001; Elliot \& Friedman, 2007; Elliot \& Thrash, 2001; Schüler et al., 2013). Avoidance motivation gives rise to fear, which hinders effective functioning and impairs well-being (Elliot, 2005, 2008) - which should be true for cognitive as well as motor functioning.

In order to test the mediating role of avoidance motivation empirically, future studies should employ avoidance motivation measures that are suitable for young children. We recommend a mixture of self-reporting and rating by individuals involved in education (teachers) and childrearing (parents). Also, the use of psychophysiological indicators of stress (e.g., heart rate variability), which are more independent of conscious self-reflection, would shed further light on the mechanism between failure cues and reduced motor and cognitive performance in elementary school children.

\section{References}

Bargh, J. A., \& Chartrand, T. L. (1999). The unbearable automaticity of being. American Psychologist, 54, 462-479. doi 10.1037/0003-066X.54.7.462

Butler, R., \& Nisan, M. (1986). Effects of no feedback, task-related comments, and grades on intrinsic motivation and performance. Journal of Educational Psychology, 78, 210-216. doi 10.1037/0022-0663.78.3.210

Cacioppo, J. T., Gardner, W. L., \& Berntson, G. G. (1999). The affect system has parallel and integrative processing components: Form follows function. Journal of Personality and Social Psychology, 76, 839-855. doi 10.1037/0022-3514.76.5.839

Ciani, K. C., \& Sheldon, K. M. (2010). A versus F: The effects of implicit letter priming on cognitive performance. British Journal of Educational Psychology, 80, 99-119. doi 10.1348/ 000709909X466479

Covington, M. V. (1992). Making the grade: A self-worth perspective on motivation and school reform. New York: Cambridge University Press.

Deci, E. L., \& Ryan, R. M. (1985). Intrinsic motivation and selfdetermination in human behavior. New York: Plenum.

Deci, E. L., \& Ryan, R. M. (2000). The "what" and "why" of goal pursuits: Human needs and the self-determination of behavior. Psychological Inquiry, 11, 227-268.

Deutsch, M. (1979). Education and distributive justice: Some reflections on grading systems. American Psychologist, 34, 391-401. doi 10.1037/0003-066X.34.5.391

Elliot, A. J. (2005). A conceptual history of the achievement goal construct. In A. J. Elliot \& C. S. Dweck (Eds.), Handbook of competence and motivation (pp. 52-72). New York, NY: Guilford.

Elliot, A. J. (2008). Handbook of approach and avoidance motivation. New York: Taylor \& Francis.

Elliot, A. J., \& Friedman, R. (2007). Approach-avoidance: A central characteristic of personal goals. In S. D. Philips, B. R. Little, \& K. Salmela-Aro (Eds.), Personal project pursuit: Goals, action, and human flourishing (pp. 97-118). Mahwah, NJ: Erlbaum.

Elliot, A.J., \& Maier, M.A. (2007). Color and psychological functioning. Current Directions in Psychological Science, 16, 250-254. doi 10.1111/j.1467-8721.2007.00514.x

Elliot, A. J., Maier, M. A., Binser, M. J., Friedman, R., \& Pekrun, R. (2009). The effect of red on avoidance behavior in achievement contexts. Personality and Social Psychology Bulletin, 3, 365-375. doi 10.1177/0146167208328330

Elliot, A. J., Maier, M. A., Moller, A. C., Friedman, R., \& Meinhardt, J. (2007). Color and psychological functioning: The effects of red on performance attainment. Journal of Experimental Psychology: General, 136, 154-168. doi 10.1037/0096-3445.136.1.154

Elliot, A. J., \& McGregor, H. A. (1999). Test anxiety and the hierarchical model of approach and avoidance achievement motivation. Journal of Personality and Social Psychology, 76, 628-644. doi 10.1037/0022-3514.76.4.628

Elliot, A. J., \& McGregor, H. A. (2001). A $2 \times 2$ achievement goal framework. Journal of Personality and Social Psychology, 80, 501-515. doi 10.1037/0022-3514.80.3.501

Elliot, A. J., Shell, M.M., Henry, K. B., \& Maier, M. (2005). Achievement goals, performance contingencies, and performance attainment: An experimental test. Journal of Educational Psychology, 97, 630-640.

Elliot, A. J., \& Thrash, T.M. (2001). Achievement goals and the hierarchical model of achievement motivation. Educational Psychology Review, 12, 139-156. doi 10.1023/A:1009057102306

Guthrie, E. R. (1930). Conditioning as a principle of learning. Psychological Review, 37, 412-428.

Helmke, A. (1988). The role of classroom context factors for the achievement-impairing effect of test anxiety. Anxiety Research, 1, 37-52.

Kaplan, H., \& Assor, A. (2012). Enhancing autonomy-supportive I-Thou dialog in schools: Conceptualization and socioemotional effects of an intervention program. Social Psychology of Education, 15, 251-269. doi 10.1007/s11218-012-9178-2

Knowler, W. C., Barrett-Connor, E., Fowler, S. E., Hamman, R. F., Lachin, J. M., Walker, E. A., \& Nathan, D. M. (2002). Diabetes Prevention Program Research Group. Reduction in the incidence of type 2 diabetes with lifestyle intervention of metformin. New England Journal of Medicine, 346, 393-403.

Kuth, D. J. L., \& Cooper, C. (1992). Physical activity at 36 years: Patterns and childhood predictors in a longitudinal study. Journal of Epidemiology and Community Health, 46, 114-119. doi 10.1136/jech.46.2.114

Maier, M. A., Elliot, A. J., \& Lichtenfeld, S. (2008). Mediation of the negative effect of red on intellectual performance. Personality and Social Psychology Bulletin, 34, 1530-1540. doi 10.1177/0146167208323104

Oosterhof, A. (1999). Developing and using classroom assessments (2nd ed.). Upper Saddle River, NJ: Prentice-Hall.

Powell, K. E., Thompson, P.D., Caspersen, C. J., \& Kenderick, J.S. (1987), Physical activity and the incidence of coronary heart disease. Annual Review of Public Health, 8, 253-287. 
Raven, J., Raven, J. C., \& Court, J. H. (2003). Manual for Raven's Progressive Matrices and Vocabulary Scales, Section 1: General overview. San Antonio, TX: Harcourt Assessment.

Reeve, J. (2009). Why teachers adopt a controlling motivating style toward students and how they can become more autonomy supportive. Educational Psychologist, 44, 159-175. doi $10.1080 / 00461520903028990$

Ryan, R. M., \& Deci, E.L. (2002). Overview of self-determination theory: An organismic dialectical perspective. In E. L. Deci \& R. M. Ryan (Eds.), Handbook of self-determination research (pp. 3-33). Rochester, NY: Rochester University Press.

Ryan, R. M., \& Deci, E. L. (2008). Self-determination theory and the role of basic psychological needs in personality and the organization of behavior. In P. O. John, R. W. Robins, \& L. Pervin (Eds.), Handbook of personality psychology: Theory and research (3rd ed., pp. 654-678). New York: Guilford.

Schüler, J., Brandstätter, V., \& Baumann, N. (2013). The nonconscious effects of learned failure cues on avoidance motivation and cognitive performance. European Journal of Social Psychology, 43, 335-343. doi 10.1002/ejsp.1942

Seligman, M. E.P. (1971). Phobias and preparedness. Behavior Therapy, 2, 307-320.

Stiggins, R. (1997). Student-centered classroom assessment (2nd ed.). Upper Saddle River, NJ: Prentice-Hall.

Vansteenkiste, M., Niemiec, C.P., \& Soenens, B. (2010). The development of the five mini-theories of self-determination theory: An historical overview, emerging trends, and future directions. In S. A. Karabenick \& T. C. Urdan (Eds.), The decade ahead: Theoretical perspectives on motivation and achievement (pp. 105-165). Bingley, UK: Emerald Group Publishing. doi 10.1108/S0749-7423(2010)000016A007

Vansteenkiste, M., Sierens, E., Goossens, L., Soenens, B., Dochy, F., Mouratidis, A., \& Beyers, M. (2012). Identifying configurations of perceived teacher autonomy support and structure: Associations with self-regulated learning, motivation and problem behavior. Learning and Instruction, 22, 431-439. doi 10.1016/j.learninstruc.2012.04.002

Wagner, C., \& Valtin, R. (2003). Noten oder Verbalbeurteilungen? Die Wirkung unterschiedlicher Bewertungsformen auf die schulische Entwicklung von Grundschulkindern [Marks or verbal reports? The effect of different assessment forms on school development of elementary school children]. Zeitschrift für Entwicklungspsychologie und Pädagogische Psychologie, $35,27-36$. 